\title{
Greater Swiss Mountain Dog
}

National Cancer Institute

\section{Source}

National Cancer Institute. Greater Swiss Mountain Dog. NCI Thesaurus. Code C53769.

The Greater Swiss Mountain Dog is a large, strong, muscular, draft dog. The head is large with a broad, flat skull and pendant, medium-sized, triangular ears. The coat is a tricolor double coat (black with rust and white markings). Height: 23.5-28.5 (60-72 cm.) Weight: 130-135 pounds (59-61 kg.) 